\title{
Which is the "lord" of the aortic rings?
}

\author{
Ehud Raanani, MD
}

From the Department of Cardiac Surgery, Sackler School of Medicine, Tel Aviv University, Tel Aviv, Israel

Disclosures: Author has nothing to disclose with regard to commercial support.

Received for publication Dec 27, 2015; accepted for publication Dec 30, 2015; available ahead of print Jan 30, 2016.

Address for reprints: Ehud Raanani, MD, Department of Cardiac Surgery, Sheba Medical Center, Tel Hashomer,

52621, Israel (E-mail: ehud.raanani@sheba.health.gov.il).

J Thorac Cardiovasc Surg 2016;151:1286-7

0022-5223/\$36.00

Copyright (c) 2016 by The American Association for Thoracic Surgery

http://dx.doi.org/10.1016/j.jtcvs.2015.12.043

In this issue of the Journal, Basmadjian and colleagues ${ }^{1}$ from Montreal present their experience with external aortic rings for the stabilization of the aortic annulus in 50 patients who underwent aortic root remodeling or the Ross procedure. They used 39 Dacron polyester fabric rings and 11 commercially available Extra-Aortic rings (CORONÉO Inc, Montreal, Canada), which were implanted under a Special Access Program pending Health Canada regulatory approval. They showed that during short-term to midterm follow-up (median of 12 months), this procedure provided stability and some maintenance of systolic extensibility of the aortic annulus.

This article highlights the importance of aortic annular stabilization. Stabilizing the aortic annulus, or to be more accurate the aortoventricular junction (AVJ), has become a major contributing factor in providing excellent shortand long-term results of aortic valve preservation and repair surgery. The importance of stabilizing the AVJ lies in the fact that most patients who undergo these procedures have some type of diagnosed or undiagnosed connective tissue disease. In connective tissue diseases, the AVJ, as part of the heart's fibroskeleton, is prone to dilation with time. The correct AVJ diameter is part of the geometry of the normal aortic root complex. Dilatation of the AVJ has been shown clinically and also by the use of computer finite element models $^{2,3}$ (Figure 1) to be associated with aortic insufficiency as a result of its ability to cause aortic cusp prolapse. In patients undergoing aortic valve preservation or repair, the AVJ is likely either to be already dilated at the time of surgery or to dilate later should the patient live long enough. Once the AVJ dilates, the patient will experience recurrent aortic insufficiency as a result of aortic cusp prolapse.

It is important to be aware of this information and to incorporate it into daily practice. It is relevant for all cases of aortic valve repair and root remodeling, as well as in the Ross procedure, where root dilatation is known to be one of the failure mechanisms.

The true aortic annulus (AVJ) is located deep in the heart, at the base of the aortic root. Because of its difficult-to-reach location, multiple surgical maneuvers

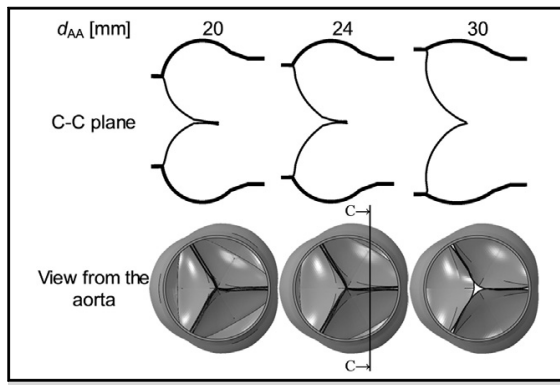

Dilated aortic annulus induces cusp prolapse and reduces cusp coaptation.

\section{Central Message}

$\overline{\text { Aortic annuloplasty positively affects aortic }}$ valve geometry and prevents future dilation. It is a key to any aortic valve-preserving surgery.

See Article page 1280 .

have been suggested and used through the years for AVJ stabilization. Cabrol and colleagues ${ }^{4}$ were the first to suggest partial annuloplasty with subcommissural sutures. Because of its simplicity, this technique was widely adopted for many years, but it has recently been abandoned because of its unfavorable long-term results, with significant rates of recurrent aortic insufficiency. Various other types of aortic rings - partial or complete, flexible or rigid, external or internal, and synthetic or biologic-have also been introduced. To date, none of them have gained widespread popularity because of their complexity, difficulty to reproduce, or unfavorable or unproven long-term results.

Nevertheless, one concept for AVJ stabilization has passed the test of time, and that is the aortic valve reimplantation technique, a concept introduced many years ago by David and associates. ${ }^{5}$ In this procedure, sutures are passed in a circular fashion from the left ventricular outflow tract just below the aortic cusps to the outside of the aortic root. This method not only provides complete $360^{\circ}$ support but enables the sutures and the lower part of the Dacron polyester fabric tube to hug the entire basal and virtual rings of the aortic root, which in turn preserves definite stability of the AVJ. This technique has been shown to be effective in several long-term clinical studies by David and others. The disadvantages of this technique are that it requires significant dissection to the base of the aortic root and that it is used for aortic root replacement rather than for valve repair. Aicher and coworkers ${ }^{6}$ have reported excellent midterm results with external suture annuloplasty used in both aortic valve repair and aortic root remodeling 


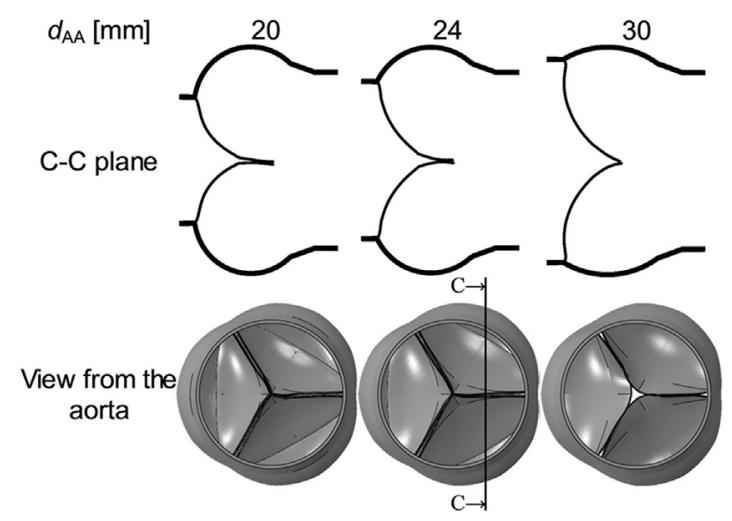

FIGURE 1. Three different aortic root geometries show that dilated aortic annulus induces cusp prolapse and reduces cusp coaptation.

surgery. The advantage of this technique is its simplicity and avoidance of the need to dissect through the base of the aortic root. There are, however, 2 main concerns: (1) the possible unclear exact location and level of where to pass the suture and (2) the fact that the aortic root systolic forces are distributed along a relatively thin suture and not along a wider band. This promising procedure therefore needs longer follow-up time.

The Extra-Aortic ring (CORONÉO), developed and made popular by Lansac and colleagues, ${ }^{7}$ has the potential to become the optimal solution, or at least the best compromise, of all the options. It provides the optimal stabilization concept, like that of the David procedure combined with a standardized solution for aortic valve repair (when there is no need for root replacement), as well providing an option for those who choose to perform the remodeling technique (Yacoub or Schäfers). It is also important, however, to realize that it is not a "simple" or "innocent" maneuver but rather a surgical procedure that takes significant crossclamp time to perform and one that requires a sound understanding of the anatomy of the heart.

\section{References}

1. Basmadjian L, Basmadjian AJ, Stevens LM, Mongeon FP, Cartier R, Poirier N et al. Early results of extra-aortic annuloplasty ring implantation on aortic annular dimensions. J Thorac Cardiovasc Surg. 2016;151:1280-5.e1.

2. Aicher D, Kunihara T, Abou Issa O, Brittner B, Gräber S, Schäfers HJ. Valve configuration determines long-term results after repair of the bicuspid aortic valve Circulation. 2011;123:178-85.

3. Marom G, Haj-Ali R, Rosenfeld M, Schäfers HJ, Raanani E. Aortic root numeric model: annulus diameter prediction of effective height and coaptation in postaortic valve repair. J Thorac Cardiovasc Surg. 2013;145:406-11.e1.

4. Cabrol C, Cabrol A, Guiraudon G, Bertrand M. Treatment of aortic insufficiency by means of aortic annuloplasty [in French]. Arch Mal Coeur Vaiss. 1966;59:1305-12.

5. David TE, Feindel CM, David CM, Manlhiot C. A quarter of a century of experience with aortic valve-sparing operations. J Thoracic Cardiovasc Surg. 2014;148: 872-9; discussion 879-80.

6. Aicher D, Schneider U, Schmied W, Kunihara T, Tochii M, Schäfers HJ. Early results with annular support in reconstruction of the bicuspid aortic valve. J Thorac Cardiovasc Surg. 2013;145(3 Suppl):S30-4.

7. Lansac E, Di Centa I, Raoux F, Bulman-Fleming N, Ranga A, Abed A, et al. An expansible aortic ring for a physiological approach to conservative aortic valve surgery. J Thorac Cardiovasc Surg. 2009;138:718-24. 